\title{
Stronger and More Vulnerable: A Balanced View of the Impacts of the NICU Experience on Parents
}

\author{
Annie Janvier, MD, PhD, ${ }^{a}$ John Lantos, MD, ${ }^{b}$ Judy Aschner, MD, ${ }^{c}$ Keith Barrington, MB, ChB, ${ }^{a}$ Beau Batton, MD, ${ }^{d}$ Daniel \\ Batton, MD, ${ }^{d}$ Siri Fuglem Berg, MD, PhD, e Brian Carter, MD, ${ }^{b}$ Deborah Campbell, MD, FAAP, ${ }^{c}$ Felicia Cohn, PhD, ${ }^{f}$ Anne Drapkin

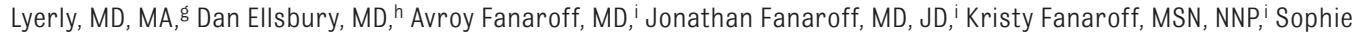 \\ Gravel, BNurs, ${ }^{a}$ Marlyse Haward, MD, ${ }^{j}$ Stefan Kutzsche, MD, PhD, ${ }^{k}$ Neil Marlow, DM, FMedSci,' Martha Montello, PhD, ${ }^{m}$ \\ Nathalie Maitre, MD, PhD, ${ }^{n}$ Joshua T. Morris, MDiv, BCC, ${ }^{0}$ Odd G. Paulsen, MD, ${ }^{p}$ Trisha Prentice, MBBS, ${ }^{q}$ Alan R. Spitzer, MD ${ }^{h}$
}

For parents, the experience of having an infant in the NICU is often psychologically traumatic. No parent can be fully prepared for the extreme stress and range of emotions of caring for a critically ill newborn. As health care providers familiar with the NICU, we thought that we understood the impact of the NICU on parents. But we were not prepared to see the children in our own families as NICU patients. Here are some of the lessons our NICU experience has taught us. We offer these lessons in the hope of helping health professionals consider a balanced view of the NICU's impact on families.

For parents, the experience of having an infant in the NICU is often psychologically traumatic. No parent can be fully prepared for the extreme stress and range of emotions of caring for a critically ill newborn. Many studies have documented the anxiety, depression, insomnia, grief, and posttraumatic stress symptoms that parents experience. ${ }^{1}$ These studies are important because they help us to understand, to empathize, and maybe even to discover ways to improve families' experiences. However, such studies are also incomplete and tell only part of the story. Most are conducted in the first months or years after the NICU hospitalization, when the infants and their parents are still fragile. They generally do not report how parents' feelings, perceptions, and coping mechanisms change over the years.

A different set of studies, from other domains of medicine and pediatrics, has investigated the longer term effects of a critical illness. These studies show that positive transformations often follow traumatic life-altering events. In the medical literature, these changes are referred to as posttraumatic growth. ${ }^{2}$ They have been reported most frequently in adults: for example, cancer survivors, trauma victims, HIV-infected individuals, and those with spinal cord injuries. Recent investigations, however, have shown that posttraumatic growth also occurs for children and families after the serious illness of a child. ${ }^{3}$ Many factors are associated with resilience, including socioeconomic status, the nature and permanence of the health condition, patient/parent psychological state, and family/social/societal support. Unfortunately, investigations relating to positive family transformations after neonatal hospitalizations are scarce. They have been described for parents of children with Down syndrome, trisomy 18 , trisomy 13 , and cerebral palsy. ${ }^{4-6}$ However, positive effects of the NICU experience can be found in abundance outside of the medical

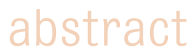

aDepartment of Pediatrics, Hôpital Saint-Justine, Montréal, Quebec, Canada; ${ }^{b}$ Children's Mercy Hospital, Kansas

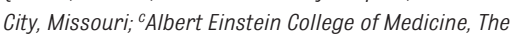
Children's Hospital at Montefiore, New York, New York ${ }^{d}$ Department of Pediatrics, Southern Illinois University School of Medicine, Springfield, Illinois; ${ }^{e}$ Municipality of Gjovik, and Innlandet Hospital Trust, Hamar, Norway; ${ }^{f}$ Bioethics, Kaiser Permanente, Oakland, California; ${ }^{g}$ Center for Bioethics and Department of Social Medicine University of North Carolina, Chapel Hill, North Carolina; hPediatrix Medical Group, Mednax, Inc, Sunrise, Florida; 'Division of Neonatology, 'Department of Pediatrics, Case Western Reserve University, Rainbow Babies and Children's Hospital, Cleveland, Ohio; ${ }^{k}$ International Medical University, Kuala Lumpur, Malaysia; 'UCL EGA Institute for Women's Health, University College London, London, United Kingdom ${ }^{m}$ Center for Bioethics, Harvard Medical School, Boston, Massachusetts; 'Department of Pediatrics, Center for Perinatal Research, Nationwide Children's Hospital and Ohio State University, Columbus, Ohio; oPediatrics, Miller Children's and Women's Hospital Long Beach, Long Beach, California; ${ }^{p}$ Department of Anesthesiology, Innlandet Hospital Trust, Hamar, Norway; and aPediatrics, Royal Children's Hospital Melbourne, Parkville, Victoria, Australia

Drs Janvier and Lantos helped to conceptualize the manuscript, reviewed drafts, and contributed to the final product; and Drs Aschner, Barrington, Beau, B. Batton, D. Batton, Fuglem, Berg, Carter, Campbell, Cohn, Drapkin, Lyerly, Ellsbury, A. Fanaroff, J. Fanaroff, Haward, Kutzsche, Maitre Marlow, Montello, Paulsen, Prentice, and Spitzer, Ms Fanaroff, Ms Gravel, and Mr Morris contributed to the design of the paper, the drafting of the manuscript, and the review of the manuscript. All authors approved the final version.

DOI: $10.1542 /$ peds.2016-0655

Accepted for publication Jun 14, 2016

To cite: Janvier A, Lantos J, Aschner J, et al. Stronger and More Vulnerable: A Balanced View of the Impacts of the NICU Experience on Parents. Pediatrics. 2016;138(3):e20160655 
literature, from first-person reports in books, memoirs, and parental blogs. ${ }^{7-9}$ Clinicians and researchers must be mindful that the negative impacts of the NICU experience are only 1 side of the story.

As health care providers familiar with the NICU, we thought that we understood the impact of the NICU on parents. But we were not prepared to see the children in our own families as NICU patients. We were not ready for the ways in which the medical jargon could be alienating to us when used to describe "our" infants. ${ }^{8}$ We were not ready for the lack of control that accompanies a typical NICU stay. Even if we are highly rational and organized individuals as providers, as parents we often gave consent for interventions with our hearts, not our heads. ${ }^{10}$ We had trouble when health care professionals attempted to be honest with us and to help us develop realistic expectations about the future. Neonatal intensive care providers were often perceived as negative and pessimistic, especially at times when we needed hope. We came to a new appreciation regarding the delicate balance that health care providers must seek between honesty and compassion, between realism and optimism.

The experience of having an infant in the NICU altered both our professional and our personal lives in profound and permanent ways. We had to slowly reinvent ourselves to be a new parent with a fragile infant, instead of the healthy infant that we had hoped for and dreamed about.

Here are some of the lessons our NICU experience has taught us. We offer them in the hope of helping health professionals consider a balanced view of the NICU's impact on families. Despite sharing similar experiences in our professional lives, our perinatal and NICU experiences were different. We all rewrote our life stories to include parts we were not prepared for; some of us had to write a chapter about being the parent of a dead child, others about being the parents of children with lifelong disabilities. Our children have grown. Some are now 1 year old; others are $>30$ years old. We are not the same people nor the same providers we were before being parents in the NICU. For many, these are a series of small transformations. All of us had to rebuild ourselves after our challenging perinatal and NICU experiences that, to some degree, destroyed who we were. We share our perspective of a life transformation rather than a "posttraumatic growth." We did not grow. We are stronger and yet more vulnerable. Families' reports of positive transformations outside of the medical literature resonate with our experiences. All families have unique and different experiences, but many will learn similar lessons.

\section{GRATITUDE}

Gratitude for the gift of life, for simple and important things in life. Gratitude for our families and friends, for skilled professionals, for the kindnesses of strangers. We understand every day, with our hearts, that we have much to be grateful for.

\section{PERSPECTIVE}

Learning to not sweat the small stuff and to recognize what is truly precious. We now pay less attention to things that are not worth fussing over and fight like hell for the things that are. We now see that perfection is in many places where we could not see it before. Perfection does not necessarily equate with percentages, excellence, performance, high grades, beauty, speed, or quantity.

\section{LACK OF CONTROL}

One of the most difficult things for a parent to recognize is that many things are beyond our control. We now focus on controlling the things that we can but recognize when there are things that we cannot. We no longer plan and predict what may happen with every possible decision. Often, life does not follow our predictions.

\section{DECIDING WITH THE HEART}

We have experienced the limitations of informed consent, statistics, probabilities, and predictions. We know that being informed repeatedly that something bad may happen to $\mathrm{X} \%$ of infants does not help much; parents do not have 100 infants. We have gained a new appreciation of uncertainty, of the role of emotions in decision-making. We know that vulnerability and emotions are sources of strength. They allow us to connect with our passion and purpose, to become happier, more compassionate, and more hopeful as human beings and as providers.

\section{CONNECTEDNESS}

In whole new ways, we have come to understand the importance of family and relationships and the need to nurture precious connections. In the most difficult moments in life, some people held us while others disappeared. The NICU experience reminds us how important it is to be there for those who matter in our lives.

\section{RESILIENCE}

We learned that we are stronger than we think. We now know it is possible to see our hopes, dreams, and plans totally destroyed and then to rewrite our story with a new plotline. We can adapt. We can experience a "freedom from fear" when dealing with life challenges or with the imperfections of the health care system. We rarely look backward and regret.

\section{HUMILITY}

We are more humble about the powers of science. As providers, 
we had thought about what we would do as parents if tragic things happened to our children. We were convinced we knew what we would do. However, faced with reality, we often did not act in ways we thought we would: more important thoughts came through our heads, more important values we did not predict. We now have a much greater respect for how to act in unexpected scenarios, in situations of uncertainty. We are more flexible.

\section{FORGIVENESS}

Having a sick infant is often associated with parental guilt or grief. The ability to "move on" not only takes time but requires forgiveness. Forgiveness to ourselves, for what we perhaps could have, should have, done or been. For those of us whose child dies, we must forgive ourselves when, in time, we realize that life goes on. Forgiveness for those who disappeared when we needed them, for real and perceived human failings of our families or friends or providers. We have learned that forgiveness is a journey and apply that understanding to other spheres of our lives.

\section{DEDICATION}

We are more dedicated to excellence in clinical care. We witnessed the pure beauty of bedside clinical excellence, which we sometimes found in unexpected places and with all types of health care providers. We learned the power of small gestures, the deep impact of an extra effort, a genuine smile, or a kind word. We also met some less competent people. We are now intolerant of mediocrity and uncompromising with regard to patient care.

\section{RECOMMENDATIONS TO CLINICIANS AND RESEARCHERS}

1. Be aware that parents experience both negative and positive impacts after an NICU experience. Researchers examining these outcomes should investigate both sides of the story. Communications with parents should be balanced.

2. Remain humble. Avoid sentences such as: "Parents don't understand" or "If I were in their situation, I would not...." Too often, it is providers who do not understand.

3. Tell parents that they did not choose the misfortunes that are happening to their infant, that there is nothing they could have done to prevent this. Remind them often that their infant is lucky to have parents who love him or her.

4. Let parents know that positive transformations are possible.

5. Temper discussions about risks with words about something good happening, such as resilience, love, and the chances of healing.

6. Help parents prioritize their energy and how to recognize what they can and cannot control. Encourage them to let go where they can.

7. Inform parents that life will not always be like this, that the roller coaster will become a train with a known destination. That one day, it will be better. That they are stronger than they think. That they have to believe it.

8. We can be there for parents at tough moments or avoid them. Be there.

These lessons do not in any way attempt to sugarcoat or diminish the difficult and bitter reality of having an infant in the NICU. However, parental NICU experiences may be improved by balancing the cold, hard facts, bleak outcomes, and psychological toll with the insights we offer. Most parents are resilient. They advocate for their child in ways they cannot or would not advocate for themselves. The realization of their own strength and resilience will lead to "life transformations" that allow the world to make sense again and their families to rebuild themselves and write a new story.

\section{MORE ON THE POST GROUP AUTHORS (IN ALPHABETICAL ORDER) AND THEIR "NICU CHILDREN"}

Judy Aschner (neonatologist) is the mother of Nadav, who was born at 31 weeks after rupture of membranes at 21 weeks' gestational age (GA).

Beau Batton (neonatologist) is the father, and Daniel Batton (neonatologist) is the grandfather, of Charlie, who was born with a univentricular heart.

Siri F. Berg (anesthesiologist) and Odd G. Paulsen (anesthesiologist and emergency physician) are the parents of Evy Kristine, who was born with trisomy 18 and died of cardiac failure.

Deborah Campbell (neonatologist) is the mother of Courtney Alexis, born at 27 weeks during a pregnancy complicated by preeclampsia and massive abruption. Courtney died at 28 days of age.

Brian Carter (neonatologist, palliative care physician, and clinical ethicist) is the father of Sean, who was born at 34 weeks' GA.

Felicia Cohn (clinical ethicist) is the mother of Amanda, who was born with transposition of the great vessels.

Dan Ellsbury (neonatologist) is the father of Codey, Kyle, and Hope. Codey and Kyle were born at 28 weeks' GA. Kyle died of complications of prematurity and BeckwithWiedemann syndrome. Hope was born with hypoplastic left heart syndrome.

Jonathan Fanaroff (neonatologist and bioethicist) and Kristy Fanaroff (neonatal nurse practitioner) are the parents of Mason, who was born at 32 weeks' GA. Avroy Fanaroff 
(neonatologist) is the grandfather of Mason and the father of Jonathan, who was critically ill at birth with meconium aspiration syndrome.

Sophie Gravel (chief NICU nurse) is the mother of Roxanne, who was born with in utero volvulus at 29 weeks.

Marlyse Haward (neonatologist and bioethicist) is the mother of Charlie, who was diagnosed in utero with congenital anomalies. He is now doing well.

Annie Janvier (neonatologist and clinical ethicist) and Keith Barrington (neonatologist) are the parents of Violette, who was born at 24 weeks' GA.

Stefan Kutzsche (neonatologist and anesthesiologist) is the grandfather of Jakob and Vegard, twins who were born at 25 weeks' GA.

John Lantos (pediatrician and clinical ethicist) and Martha Montello (clinical ethicist) are the grandparents of Sam and Will, who were born at 23 weeks' GA. Sam died of complications of prematurity.

Anne Drapkin Lyerly (obstetrician and bioethicist) is the mother of Will, who was born at term with an intraabdominal mass.

Nathalie Maitre (neonatologist, follow-up physician, and researcher) is the mother of Leo, who was born at 27 weeks' GA, and Lucas, who was born at 36 weeks' GA.

Neil Marlow (neonatologist) is the father of Tom and Simon, who were born at 30 weeks' GA.
Joshua T. Morris (pediatric hospital chaplain) is the father of Isaac, who was born at 28 weeks' GA.

Trisha Prentice (neonatologist and doctoral candidate) is the mother of Jordain, who was born at 28 weeks' GA.

Alan R. Spitzer (neonatologist and researcher) is the grandfather of Jacob, Matthew, Alexandra, and Shaun, born at 29, 36, 35, and 35 weeks' GA, respectively.

\section{ABBREVIATION}

GA: gestational age

Address correspondence to John D. Lantos, MD, Children's Mercy Hospital, 2401 Gillham Rd, Kansas City, M0 64108. E-mail: jlantos@cmh.edu PEDIATRICS (ISSN Numbers: Print, 0031-4005; Online, 1098-4275).

Copyright (C) 2016 by the American Academy of Pediatrics

FINANCIAL DISCLOSURE: The authors have indicated they have no financial relationships relevant to this article to disclose.

FUNDING: No external funding.

POTENTIAL CONFLICT OF INTEREST: The authors have indicated they have no potential conflicts of interest to disclose.

\section{REFERENCES}

1. Kim WJ, Lee E, Kim KR, Namkoong K, Park ES, Rha DW. Progress of PTSD symptoms following birth: a prospective study in mothers of high-risk infants. J Perinatol. 2015;35(8):575-579

2. Linley PA, Joseph S. Positive change following trauma and adversity: a review. J Trauma Stress. 2004;17(1):11-21

3. Picoraro JA, Womer JW, Kazak AE, Feudtner C. Posttraumatic growth in parents and pediatric patients. J Palliat Med. 2014;17 (2):209-218

4. Scorgie K, Sobsey D. Transformational outcomes associated with parenting children who have disabilities. Ment Retard. 2000;38(3):195-206

5. Janvier A, Farlow B, Wilfond BS. The experience of families with children with trisomy 13 and 18 in social networks. Pediatrics. 2012;130(2):293-298

6. Skotko BG, Levine SP, Macklin EA, Goldstein RD. Family perspectives about Down syndrome. Am J Med Genet A. 2016;170(4): 930-941

7. March of Dimes. "2 here 2 in Heaven." What my children have taught me. Available at: http:// share.marchofdimes.org/blog/b/ weblog18812/archive/2007/04/20/ what-my-children-have-taught-me\#. Vr40lvnhAgs. Accessed February 12, 2016

8. Thiele P, Berg SF, Farlow B. More than a diagnosis. Acta Paediatr. 2013;102(12):1127-1129

9. Janvier A. Ces choses que Violette m'a apprises (These things that Violette taught me). Respire, bébé, respire! Prématurités et naissances difficiles. Quebec, Canada: Québec Amérique; 2015

10. Cohn F. Suddenly "I" was a "them." Curr Probl Pediatr Adolesc Health Care. 2011;41(4):111-112 


\section{Stronger and More Vulnerable: A Balanced View of the Impacts of the NICU Experience on Parents}

Annie Janvier, John Lantos, Judy Aschner, Keith Barrington, Beau Batton, Daniel Batton, Siri Fuglem Berg, Brian Carter, Deborah Campbell, Felicia Cohn, Anne Drapkin Lyerly, Dan Ellsbury, Avroy Fanaroff, Jonathan Fanaroff, Kristy Fanaroff, Sophie Gravel, Marlyse Haward, Stefan Kutzsche, Neil Marlow, Martha Montello, Nathalie Maitre, Joshua T. Morris, Odd G. Paulsen, Trisha Prentice and Alan R. Spitzer

Pediatrics 2016;138;

DOI: 10.1542/peds.2016-0655 originally published online August 3, 2016;

$\begin{array}{ll}\text { Updated Information \& } & \begin{array}{l}\text { including high resolution figures, can be found at: } \\ \text { hervices }\end{array} \\ \text { Reftp://pediatrics.aappublications.org/content/138/3/e20160655 } & \begin{array}{l}\text { This article cites } 8 \text { articles, } 1 \text { of which you can access for free at: } \\ \text { http://pediatrics.aappublications.org/content/138/3/e20160655\#BIBL }\end{array} \\ \text { Subspecialty Collections } & \begin{array}{l}\text { This article, along with others on similar topics, appears in the } \\ \text { following collection(s): } \\ \text { Ethics/Bioethics } \\ \text { http://www.aappublications.org/cgi/collection/ethics:bioethics_sub } \\ \text { Advocacy } \\ \text { http://www.aappublications.org/cgi/collection/advocacy_sub }\end{array} \\ \text { Permissions \& Licensing } & \begin{array}{l}\text { Information about reproducing this article in parts (figures, tables) or } \\ \text { in its entirety can be found online at: } \\ \text { http://www.aappublications.org/site/misc/Permissions.xhtml } \\ \text { Information about ordering reprints can be found online: } \\ \text { http://www.aappublications.org/site/misc/reprints.xhtml }\end{array} \\ \text { Reprints } & \end{array}$




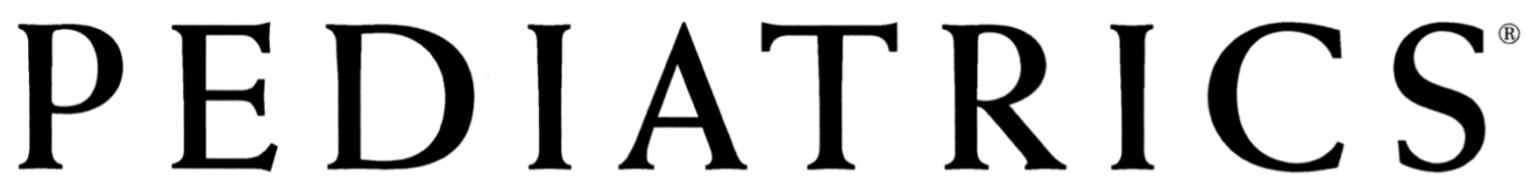

OFFICIAL JOURNAL OF THE AMERICAN ACADEMY OF PEDIATRICS

\section{Stronger and More Vulnerable: A Balanced View of the Impacts of the NICU Experience on Parents}

Annie Janvier, John Lantos, Judy Aschner, Keith Barrington, Beau Batton, Daniel Batton, Siri Fuglem Berg, Brian Carter, Deborah Campbell, Felicia Cohn, Anne

Drapkin Lyerly, Dan Ellsbury, Avroy Fanaroff, Jonathan Fanaroff, Kristy Fanaroff, Sophie Gravel, Marlyse Haward, Stefan Kutzsche, Neil Marlow, Martha Montello, Nathalie Maitre, Joshua T. Morris, Odd G. Paulsen, Trisha Prentice and Alan R.

Spitzer

Pediatrics 2016;138;

DOI: 10.1542/peds.2016-0655 originally published online August 3, 2016;

The online version of this article, along with updated information and services, is located on the World Wide Web at:

http://pediatrics.aappublications.org/content/138/3/e20160655

Pediatrics is the official journal of the American Academy of Pediatrics. A monthly publication, it has been published continuously since 1948. Pediatrics is owned, published, and trademarked by the American Academy of Pediatrics, 141 Northwest Point Boulevard, Elk Grove Village, Illinois, 60007. Copyright (C) 2016 by the American Academy of Pediatrics. All rights reserved. Print ISSN: 1073-0397. 